\title{
Highly glycated oxyhaemoglobin impairs nitric oxide relaxations in human mesenteric microvessels
}

\author{
S. Vallejo ${ }^{1}$, J. Angulo ${ }^{1}$, C. Peiró ${ }^{2}$, J.Nevado ${ }^{2}$, A.Sánchez-Ferrer ${ }^{1}$, R.Petidier ${ }^{1}$, C.F. Sánchez-Ferrer ${ }^{2}$, \\ L. Rodríguez-Mañas ${ }^{1}$ \\ ${ }^{1}$ Research Unit and Service of Geriatrics, University Hospital of Getafe, Getafe, Madrid, Spain \\ ${ }^{2}$ Department of Pharmacology, Faculty of Medicine, Autonomous University of Madrid, Madrid, Spain
}

\section{Abstract}

Aims/hypothesis. It has been recently shown that glycated human haemoglobin induces endothelial dysfunction in rat vessels by generating superoxide anions that interfere with nitric oxide mediated responses. Our study analysed the effect of glycated human haemoglobin on the endothelium-dependent relaxations of human vessels.

Methods. Omental microvessels were obtained from patients (without diabetes, hypertension or vascular disease) during surgery and mounted in a small vessel myograph to study their vasoactive responses (vessels from 3-7 patients for each set of experiments).

Results. Cumulative vasodilatory responses to bradykinin $(10 \mathrm{nmol} / \mathrm{l}$ to $3 \mu \mathrm{mol} / \mathrm{l})$ were induced in vessels precontracted with $35-50 \mathrm{mmol} / \mathrm{l}$ potassium chloride. Addition of $100 \mu \mathrm{mol} / \mathrm{l} N^{\mathrm{G}}$-nitro-L-arginine methyl ester reduced the relaxation evoked by bradykinin, but preincubation with both $N^{\mathrm{G}}$-nitro-L-arginine methyl ester and $10 \mu \mathrm{mol} / \mathrm{l}$ indomethacin was needed to abolish it. Bradykinin-induced responses were inhibited by $1 \mu \mathrm{mol} / 1$ non-glycated oxyhaemoglobin whereas no effect was obtained with $10 \mathrm{nmol} / \mathrm{l}$ oxyhaemoglobin. At these low concentrations (10 $\mathrm{nmol} / \mathrm{l}$ ), glycated human oxyhaemoglobin caused an impairment of bradykinin-induced relaxation when the percentage of glycation was $10 \%$ or higher. This effect was prevented by preincubating the vessels with ascorbic acid $(10 \mu \mathrm{mol} / \mathrm{l})$, superoxide dismutase $(100 \mathrm{U} / \mathrm{ml})$ and gliclazide $(1$ and $10 \mu \mathrm{mol} / \mathrm{l})$, but not with indomethacin $(10 \mu \mathrm{mol} / \mathrm{l})$, catalase $(400-600 \mathrm{U} /$ $\mathrm{ml})$, dimethylthiourea $(1 \mathrm{mmol} / \mathrm{l})$ or glibenclamide $(10 \mu \mathrm{mol} / \mathrm{l})$. In vessels preincubated with $N^{\mathrm{G}}$-nitro-Larginine methyl ester $(100 \mu \mathrm{mol} / \mathrm{l})$, glycohaemoglobin did not add any additional effect.

Conclusion/interpretation. Highly glycated human oxyhaemoglobin, at physiological plasmatic concentrations, impairs nitric oxide-mediated responses by a mechanism involving superoxide anions but not cyclooxygenase derivatives. [Diabetologia (2000) 43: 83-90].

Keywords Glycated haemoglobin, endothelial dysfunction, nitric oxide, superoxide anions, antioxidants, human microvessels.
The impairment of endothelium-dependent vascular relaxation, reported in animal models of diabetes and diabetic patients [1,2], has emerged as an added

Received: 19 May 1999 and in revised form: 17 August 1999

Corresponding author: L. Rodríguez-Mañas, Unidad de Investigación y $\mathrm{S}^{\circ}$ de Geriatría, Hospital Universitario de Getafe, Ctra. De Toledo, Km. 12,500.28905-Getafe (Madrid), Spain Abbreviations: BK, Bradykinin; GHHb, glycated human oxyhaemoglobin; $\mathrm{HHb}$, non-glycated human oxyhaemoalobin; KHS, Krebs-Henseleit solution; L-NAME, $N^{\mathrm{G}}$-nitro-L-arginine methyl ester; NO, nitric oxide; SOD, superoxide dismutase, DMTU, dimethylthiourea. mechanism in producing the vascular dysfunction associated with diabetes mellitus. Substances derived from the non-enzymatic protein glycation, among many others, have been involved in the impairment of nitric oxide (NO)-mediated vascular responses, namely the so called advanced glycation end products [3]. Previous works have indicated that increased values of glycated haemoglobin, an early product from the non-enzymatic glycation of haemoglobin, could also have impaired these vascular responses [4], possibly through an interference with nitric oxide by the generation of superoxide anions [5]. This occurrence possibly has an importance in the pathophysiology 
of diabetic vascular complications because haemoglobin circulates freely (not bound to haptoglobin) at nanomolar concentrations [6, 7]. Moreover, our laboratory has recently reported a high correlation between the percentage of $\mathrm{HbA}_{1 \mathrm{c}}$ and the existence of endothelial dysfunction in rats with streptozotocin-induced diabetes $[8,9]$. There is no data, however, about the potential effect of the glycation of human oxyhaemoglobin on the endothelium-dependent responses in the human vasculature.

In this regard, the aims of our study were 1) to investigate the effect of glycated human haemoglobin, at several percentages of glycation, on the endothelium-dependent responses in mesenteric microvessels from subjects without vascular disease; 2) to investigate the role of free radicals in connection with the effect of glycated haemoglobin, if any, and finally, $3)$ to evaluate the effect of two oral hypoglycaemic agents with or without antioxidant properties (gliclazide and glibenclamide, respectively) [10-12].

\section{Subjects and methods}

Biological material. Selection and exclusion criteria of patients. Omental arteries were obtained from patients $(n=52 ; 22 \mathrm{fe}-$ males, 30 males) in non-urgent, non-septic abdominal surgeries. The mean age was $47.5 \pm 2.6$ years (range: $22-64$ ). Patients with a history of diabetes, hypertension (systolic blood pressure $\geq 140 \mathrm{mmHg}$ or diastolic blood pressure $\geq 90$ ), evidence of large vessel disease (history of coronary, cerebral or peripheral vascular disease), any other pathology known to be associated with vascular alterations (such nephropathy or retinopathy), high total or low density lipoprotein cholesterol $(\geq 7$ and/or $>5 \mathrm{mmol} / \mathrm{l}$ respectively), smoking or taking any drug that might influence endothelial cell function or vascular tone (lipid lowering drugs, fibrinolysis enhancing drugs, diuretics, hypotensive agents, vasodilators, sympathomimetics, pentoxifyline, fibrinogen lowering drugs, anticoagulants, nitrates) were excluded. Patients taking aspirin, non-steroidal anti-inflammatory drugs or antioxidants (vitamin $\mathrm{C}$ or $\mathrm{E}$ ) intermittently were included.

Isometric tension recording. After removing a piece of epiplon $\left(5 \times 5 \mathrm{~cm}^{2}\right)$, it was immediately placed in a recipient containing Krebs-Henseleit solution (KHS) and heparin $(0.05 \%)$ at $4{ }^{\circ} \mathrm{C}$, previously bubbled with a $95 \% \mathrm{O}_{2}-5 \% \mathrm{CO}_{2}$ mixture. The arteries (mean internal diameter $\pm \mathrm{SE}$ mean: $309.1 \pm 9.2 \mu \mathrm{m}$ ) were cleaned of fat and connective tissue under a light microscope in a Petri dish containing KHS at $4^{\circ} \mathrm{C}$ and mounted as ring preparations $(2.5 \mathrm{~mm}$ long) on a small vessel myograph $[9,13]$ to measure isometric tension. Arteries were bathed in $\mathrm{KHS}$ at $37^{\circ} \mathrm{C}$ continuously bubbled with a $95 \% \mathrm{O}_{2}-5 \% \mathrm{CO}_{2}$ mixture and their passive tension and internal circumference were determined. The arteries were then set to an internal circumference equivalent to $90 \%$ of their relaxed in situ state given under a transmural pressure of $100 \mathrm{mmHg}$ [9]. Arteries were then contracted with $125 \mathrm{mmol} / 1 \mathrm{~K}^{+}$(KKHS, equimolar substitution of $\mathrm{KCl}$ for $\mathrm{NaCl}$ in $\mathrm{KHS}$ ) for 2 min. Segments failing to produce a maximum active tension equivalent to a pressure of $100 \mathrm{mmHg}$ on the final contraction were rejected.

The bath was then washed five times with KHS and a further washout period of $30 \mathrm{~min}$ was allowed before the arteries were contracted with the concentration of $\mathrm{KCl}$ (35 to $50 \mathrm{mmol} / \mathrm{l}$ ) required to produce approximately $80 \%$ of the maximum response to KKHS. Relaxation to bradykinin (BK) was subsequently assessed by adding increasing concentrations of $\mathrm{BK}$ at $2 \mathrm{~min}$ intervals (final bath concentrations $10 \mathrm{nmol} / \mathrm{l}$ to $3 \mu \mathrm{mol} / \mathrm{l})$.

Variables studied. 1) Component(s) of the BK-induced endothelium-dependent responses in human microvessels precontracted with potassium. To test the participation of NO or cyclooxygenase-derived substances in the vasodilator responses evoked by $\mathrm{BK}$, the vascular segments were pretreated for $15 \mathrm{~min}$ before the addition of BK with $100 \mu \mathrm{mol} / 1 N^{\mathrm{G}}$-nitro-Larginine methyl ester (L-NAME), non-glycated human oxyhaemoglobin $(\mathrm{HHb} ; 10 \mathrm{nmol} / \mathrm{l}$ and $1 \mu \mathrm{mol} / \mathrm{l})$, indomethacin $(10 \mu \mathrm{mol} / \mathrm{l})$ or $\mathrm{L}-\mathrm{NAME}$ plus indomethacin.

2) Effect of glycated oxyhaemoglobin on the BK responses. For this purpose, the segments were preincubated for 15 min before the addition of BK with glycated oxyhaemoglobin $(\mathrm{GHHb} ; 10 \mathrm{nmol} / \mathrm{l})$ at several percentages $(8,10$, and $14 \%)$ of glycation.

3) Characterisation of the component of the relaxation induced by BK sensible to the effect of GHHb. In another set of experiments, vessels were preincubated for $15 \mathrm{~min}$ with 10 $\mathrm{nmol} / \mathrm{l} \mathrm{GHHb}$ plus indomethacin $(10 \mu \mathrm{mol} / \mathrm{l})$ or plus LNAME $(100 \mu \mathrm{mol} / \mathrm{l})$.

4) Effect of free radical scavengers on the interference of glycated human oxyhaemoglobin on endothelium-dependent responses. In these experiments, vessels were preincubated for $15 \mathrm{~min}$ with $10 \mathrm{nmol} / \mathrm{l} \mathrm{GHHb}$ plus ascorbic acid $(10 \mu \mathrm{mol} / \mathrm{l})$, plus $100 \mathrm{U} / \mathrm{ml}$ superoxide dismutase (SOD), plus catalase (400-600 U/ml) or plus $1 \mathrm{mmol} / 1$ dimethylthiourea (DMTU) to evaluate the participation of free radicals.

5) Effect of gliclazide and glibenclamide on the action exerted by $\mathrm{GHHb}$ on endothelium-dependent responses. Vessels were preincubated for $15 \mathrm{~min}$ with $\mathrm{GHHb}$ plus gliclazide $(0.1$; 1 ; and $10 \mu \mathrm{mol} / \mathrm{l})$ or plus glibenclamide $(10 \mu \mathrm{mol} / \mathrm{l})$.

In every experiment, papaverine $(100 \mu \mathrm{mol} / \mathrm{l})$ was added to the bath at the end of the protocol to test the indemnity of the vascular smooth muscle.

Statistical analysis. A high variability of vascular responses was expected because of the wide range of subjects used in the study. For this reason, the experiments were systematically carried out using adjacent rings from the same vessels as control and treated segments, as only one curve to BK was done in each segment. The data were normalised as established in the legends of the figures. The results are expressed as means \pm SEM. Deviations from the mean regarding the respective controls were statistically analysed using factorial two-way analysis of variance. Student's $t$ tests were used in the statistical comparison of the $\mathrm{pD}_{2}$ values, defined as the negative log of the effective dose (number of moles) required to produce half the maximum effect. A probability of less than $5 \%$ was considered significant. $P$ values were adjusted with Bonferroni correction for multiple comparisons.

Drugs used. The composition of KHS (mmol/l) was $\mathrm{NaCl} 115$, $\mathrm{CaCl} 2$ 2.5, $\mathrm{KCl}$ 4.6, KH2PO4 1.2, $\mathrm{MgSO} 4.7, \mathrm{H}_{2} \mathrm{O}$ 1.2, NaHCO3 25, glucose 11.1 and Na2EDTA 0.03. Drugs used were $\mathrm{KCl}$, bradykinin acetate, $\mathrm{CuZn}$ superoxide dismutase (EC 1.15.1.1) from bovine erythrocytes, catalase from bovine liver, dimethylthiourea, ascorbic acid, $N^{\mathrm{G}}$-nitro-L-arginine methyl ester, indomethacin, papaverine, human haemoglobin, glycohaemoglobin Al control-E (14\% glycation) and control-N (7.3\% glycation), glibenclamide, (all of them from Sigma, St. Louis, Mo. USA) and gliclazide (Servier, Courvbeoie, France). 


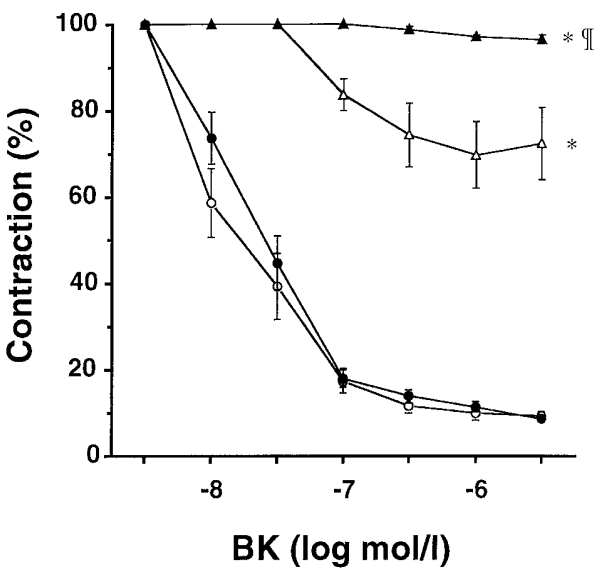

Fig.1. Relaxant responses to bradykinin (BK) in human mesenteric microvessels in untreated control segments $(\bigcirc, n=15)$, and in the presence of $10 \mu \mathrm{mol} / 1$ indomethacin $(\mathbf{C}, n=13), 100 \mu \mathrm{mol} / \mathrm{l} \mathrm{L}-\mathrm{NAME}(\Delta, n=7)$ or both $(\boldsymbol{\Delta}, n=5)$ Data are expressed as mean \pm SEM of the percentage of the residual contraction from the responses elicited by $35-50 \mathrm{mmol} / \mathrm{l} \mathrm{KCl}$, which ranged between 5 to $8 \mathrm{mN} / \mathrm{mm}$, without differences among treatments. Vascular segments used for each curve $(n)$ were obtained from at least four different patients. ${ }^{*} p<0.05$ vs control curve. $\uparrow p<0.05$ vs L-NAME

Drug solutions were made in distilled water except for indomethacin (solved in distilled water with $1.5 \mathrm{mmol} / \mathrm{l} \mathrm{Na}{ }_{2} \mathrm{H}$ $\mathrm{CO}_{3}$ ). All tested haemoglobin were prepared by reduction of commercial compounds with sodium dithionite, which were subsequently dialysed and stored in vials at $-70^{\circ} \mathrm{C}$. Concentration of oxyhaemoglobin was determined spectrophotometrically.

Ethical considerations. The experimental procedures were carried out according to the ethical guidelines of the Helsinki declaration and were approved by both the Research Committee and the Ethics Committee of the Institution. Informed consent was obtained from the patients.

\section{Results}

Component(s) of the BK-induced endothelium-dependent responses. Treatment with $35-50 \mathrm{mmol} / \mathrm{l}$ $\mathrm{KCl}$ produced a sustained vasocontractile response in human isolated microvessels, which averaged $5.98 \pm 0.37 \mathrm{mN}(n=81)$ in the absence of any drug treatment. The preincubation of the vessels with $100 \mu \mathrm{mol} / \mathrm{l}$ L-NAME, $10 \mu \mathrm{mol} / \mathrm{l}$ indomethacin, 10 nmol/l glycated haemoglobin $(8,10$, or $14 \%)$, nonglycated haemoglobin $(10 \mathrm{nmol} / \mathrm{l}$ or $1 \mu \mathrm{mol} / \mathrm{l}), 100$ $\mathrm{U} / \mathrm{ml} \mathrm{SOD}$, 400-600 U/ml catalase, $1 \mathrm{mmol} / 1 \mathrm{dim}-$ ethylthiourea, gliclazide $(0.1,1$ and $10 \mu \mathrm{mol} / \mathrm{l})$, glibenclamide $(10 \mu \mathrm{mol} / \mathrm{l})$, or ascorbic acid $(10 \mu \mathrm{mol} / \mathrm{l})$ did not modify the basal tension (data not shown) or the contractility to $\mathrm{KCl}$.

The addition of cumulative concentrations of BK $(10 \mathrm{nmol} / \mathrm{l}$ to $3 \mu \mathrm{mol} / \mathrm{l})$ induced concentration-depen-

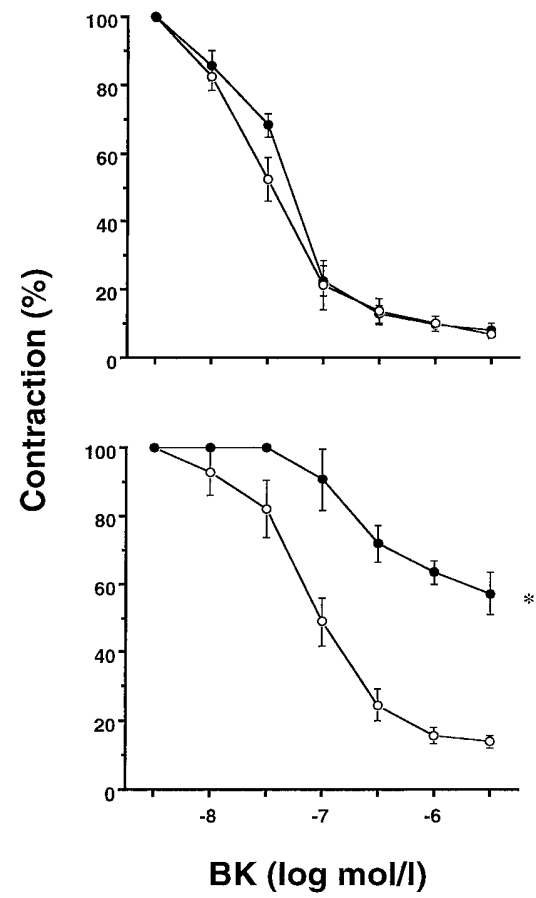

Fig. 2. Effects of (top) $10 \mathrm{nmol} / \mathrm{l}$ and (bottom) $1 \mu \mathrm{mol} / \mathrm{l}$ nonglycated human oxyhaemoglobin $(\mathrm{HHb})$ on the relaxant responses to bradykinin (BK) in human mesenteric microvessels. Groups: Control ( $\bigcirc, n=6$ and 5, respectively) and preincubated (,$n=7$ and 3 respectively) vessels. Data are expressed as means \pm SEM of the percentage of the residual contraction from the responses elicited by $35-50 \mathrm{mmol} / \mathrm{l} \mathrm{KCl}$, which ranged between 5 to $8 \mathrm{mN} / \mathrm{mm}$, without differences among treatments. Vascular segments used for each curve $(n)$ were obtained from at least three different patients. $* p<0.05$ vs respective control curve

dent relaxant responses (Fig. 1). The pretreatment of the vessels with $100 \mu \mathrm{mol} / \mathrm{l}$ L-NAME but not with $10 \mu \mathrm{mol} / 1$ indomethacin, significantly reduced the BK-evoked vasodilatation (Fig. 1). These responses were abolished in vessels preincubated with both LNAME and indomethacin.

In another set of experiments, the microvascular segments were preincubated with non-glycated oxyhaemoglobin $(\mathrm{HHb} ; 10 \mathrm{nmol} / \mathrm{l}$ or $1 \mu \mathrm{mol} / \mathrm{l})$. Note that $10 \mathrm{nmol} / \mathrm{l} \mathrm{HHb}$ had no effect on BK-evoked relaxation, whereas the concentration of $1 \mu \mathrm{mol} / \mathrm{l}$ exerted a marked reduction of such responses (Fig. 2).

Effect of several percentages of glycated oxyhaemoglobin on the BK responses. The BK-induced relaxation was significantly impaired in the presence of 10 $\mathrm{nmol} / \mathrm{l} \mathrm{GHHb}$ at $10-14 \%$ glycation. The percentage of glycation of $8 \%$, however, did not modify the vasodilatation induced by $\mathrm{BK}\left(\mathrm{pD}_{2}\right.$ values for control and preincubated vessels: $7.45 \pm 0.05$ vs $7.39 \pm 0.16$; $7.63 \pm 0.23$ vs $7.18 \pm 0.05$ and $7.56 \pm 0.19$ vs $7.02 \pm$ 0.17 for vessels preincubated with 8,10 and $14 \%$ $\mathrm{GHHb}$, respectively) (Fig. 3). 


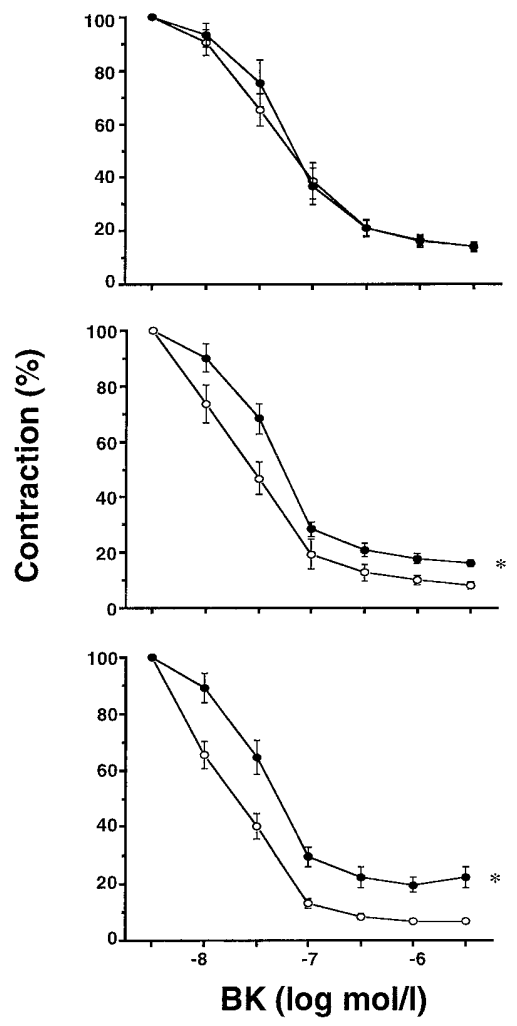

Fig.3. Effects of different $(8,10,14 \%)$ glycation percentages of human oxyhaemoglobin $(\mathrm{GHHb} ; 10 \mathrm{nmol} / \mathrm{l})$ on the relaxant responses to bradykinin (BK) in human mesenteric microvessels. Groups: Control $(\bigcirc, n=10,9$ and 19, respectively) and preincubated with $\mathrm{GHHb}(\mathcal{O}, n=8,8$ and 9, respectively). Data are expressed as means \pm SEM of the percentage of the residual contraction from the responses elicited by $35-50 \mathrm{mmol} / 1 \mathrm{KCl}$, which ranged between 5 to $8 \mathrm{mN} / \mathrm{mm}$, without differences among treatments. Vascular segments used for each curve $(n)$ were obtained from at least five different patients. $* p<0.05$ vs respective control curve

Characterisation of the component of the relaxation induced by $B K$ sensitive to the effect of $G H H b$. To further evaluate the component of the relaxation affected by the preincubation with GHHb, we tested the effect of pretreating the vessels with $10 \mu \mathrm{mol} / \mathrm{l}$ indomethacin or $100 \mu \mathrm{mol} / \mathrm{l} \mathrm{L}-\mathrm{NAME}$ on the impairment induced by $14 \% \mathrm{GHHb}$ on the BK-induced relaxation. Indomethacin did not modify the inhibitory effect of $14 \% \mathrm{GHHb}$ ( $\mathrm{pD}_{2}$ values: $6.99 \pm 0.13$ vs $7.08 \pm 0.07$ ) (Fig. 4). On the other hand, GHHb did not exert any additional effect on the significant inhibition exerted by L-NAME on the vasodilatation induced by BK (Fig. 4).

Effect of ascorbic acid, superoxide dismutase, catalase and dimethylthiourea. The pretreatment of the vessels with ascorbic acid $(10 \mu \mathrm{mol} / \mathrm{l})$ or SOD (100 U/ $\mathrm{ml})$ totally abolished the inhibitory effect of $14 \%$ $\mathrm{GHHb}$ on the vasorelaxant responses to BK (Fig.5; Table 1). Catalase $(600 \mathrm{U} / \mathrm{ml})$ nor DMTU, however, did not modify the effect of GHHb (data not shown).

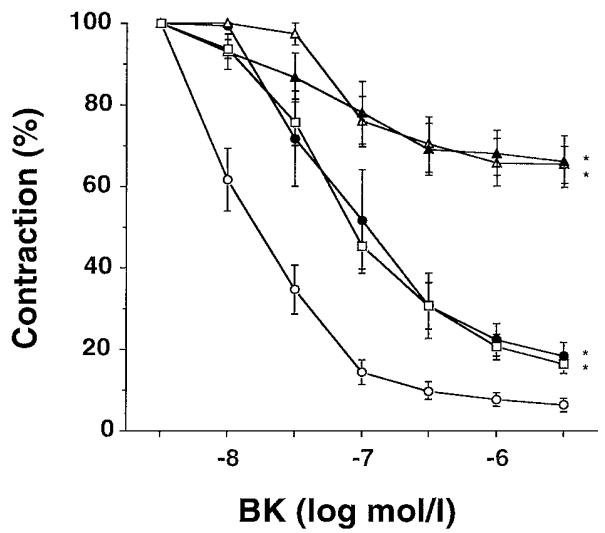

Fig. 4. Effects of preincubation with $10 \mathrm{nmol} / 1 \mathrm{1} \% \mathrm{GHHb}$ $(\mathbf{O}, n=5), 100 \mu \mathrm{mol} / 1 \mathrm{~L}-\mathrm{NAME}(\Delta, n=6,14 \%$ GHHb plus L-NAME $(\boldsymbol{\Delta}, n=6)$, and $14 \% \mathrm{GHHb}$ plus $10 \mu \mathrm{mol} / \mathrm{l}$ indomethacin $(\square, n=14)$ on the relaxant responses to bradykinin $(\mathrm{BK})$ in control vessels $(\bigcirc, n=7)$. Data are expressed as means \pm SEM of the percentage of the residual contraction from the responses elicited by $35-50 \mathrm{mmol} / \mathrm{K} \mathrm{KCl}$, which ranged between 5 to $8 \mathrm{mN} / \mathrm{mm}$, without differences among treatments. Vascular segments used for each curve $(n)$ were obtained from at least three different patients. ${ }^{*} p<0.05$ vs respective control curve

Because at that concentration, catalase induced a moderate inhibitory effect on the vasodilatation evoked by BK, we repeated those experiments using a lower concentration of catalase, $400 \mathrm{U} / \mathrm{ml}$. At this concentration, catalase did not modify the response elicited by BK nor its interference by $14 \% \mathrm{GHHb}$ (Fig.5, Table 1). None of these four substances did exert any effect on the responses induced by BK in basal (not preincubated with $\mathrm{GHHb}$ ) conditions.

Effects of gliclazide and glibenclamide on the inhibition induced by $\mathrm{GHHb}$ on endothelium-dependent responses. Preincubation with gliclazide at 1 or $10 \mu \mathrm{mol} / 1$, but not at lower concentrations, totally

Table 1. Influence of pre-treatment with $100 \mathrm{U} / \mathrm{ml}$ superoxide dismutase (SOD), $10 \mu \mathrm{mol} / \mathrm{l}$ ascorbic acid, $400 \mathrm{U} / \mathrm{ml}$ catalase and $1 \mathrm{mmol} / \mathrm{l}$ dimethylthiourea on the inhibition induced by $10 \mathrm{nmol} / \mathrm{l} 14 \%$ glycated human oxyhaemoglobin $(\mathrm{GHHb})$ on the $\mathrm{pD}_{2}$ values for bradykinin in human mesenteric microvessels

\begin{tabular}{llll}
\hline & Control & GHHb & $\begin{array}{l}\text { Pretreatment }+ \\
\text { GHHb }\end{array}$ \\
\hline SOD & $7.35 \pm 0.23$ & $6.88 \pm 0.20^{\mathrm{a}}$ & $7.48 \pm 0.26^{\mathrm{b}}$ \\
& $(N=7 ; n=27)$ & $(N=7 ; n=17)$ & $(N=3 ; n=9)$ \\
Ascorbic acid & $7.51 \pm 0.09$ & $7.09 \pm 0.14^{\mathrm{a}}$ & $7.38 \pm 0.13^{\mathrm{b}}$ \\
& $(N=4 ; n=15)$ & $(N=4 ; n=19)$ & $(N=3 ; n=7)$ \\
Catalase & $7.66 \pm 0.17$ & $6.50 \pm 0.13^{\mathrm{a}}$ & $6.69 \pm 0.24^{\mathrm{a}}$ \\
& $(N=3 ; n=7)$ & $(N=3 ; n=5)$ & $(N=3 ; n=10)$ \\
DMTU & $7.40 \pm 0.24$ & $7.02 \pm 0.07^{\mathrm{a}}$ & $7.08 \pm 0.11^{\mathrm{a}}$ \\
& $(N=3 ; n=5)$ & $(N=3 ; n=5)$ & $(N=3 ; n=6)$ \\
\hline
\end{tabular}

Data are means \pm SEM. ${ }^{\mathrm{a}} p<0.05$ vs control. ${ }^{\mathrm{b}} p<0.05$ vs analogous values without pretreatment. The number of patients $(N)$ and used segments $(n)$ are in parenthesis 

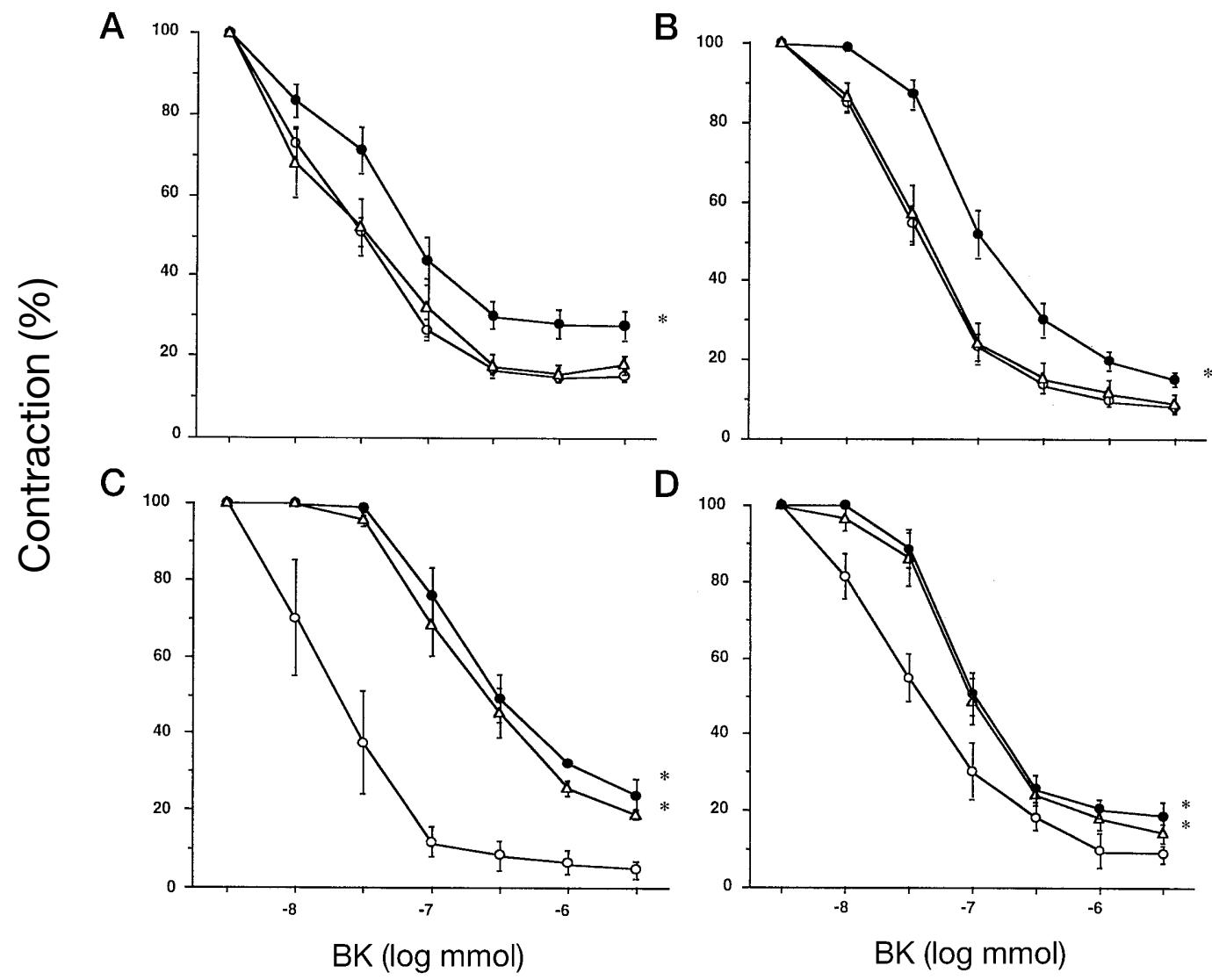

Fig. 5. Interference by A $100 \mathrm{U} / \mathrm{ml} \mathrm{SOD}(\Delta, n=9), \mathbf{B} 10 \mu \mathrm{mol} / 1$ ascorbic acid $(\Delta, n=7), \mathbf{C} 400 \mathrm{U} / \mathrm{ml}$ catalase $(\Delta, n=10)$ and D $1 \mathrm{mmol} / \mathrm{l}$ dimethylthiourea $(\Delta, n=6)$ with the impairment induced by $10 \mathrm{nmol} / 114 \% \mathrm{GHHb}(\boldsymbol{O}, n=17,15,5$ and 5 respectively) on the control ( $\bigcirc, n=27,19,7$ and 5 respectively) responses to bradykinin (BK) in human mesenteric microvessels. Data are expressed as means \pm SEM of the percentage of the residual contraction from the responses elicited by $35-50 \mathrm{mmol} / 1 \mathrm{KCl}$, which ranged between 5 to $8 \mathrm{mN} / \mathrm{mm}$, without differences among treatments. Vascular segments used for each curve $(n)$ were obtained from at least three different patients. ${ }^{*} p<0.05$ vs respective control curve

prevented the inhibitory effect of $14 \%$ GHHb (Fig. 6; Table 2). In contrast, glibenclamide at a high concentration $(10 \mu \mathrm{mol} / \mathrm{l})$, did not show any significant effect on this inhibition. $\left(\mathrm{pD}_{2}\right.$ values: $7.40 \pm 0.06$; $6.93 \pm 0.09 ; 6.97 \pm 0.08$ for control, preincubated with $10 \mathrm{nmol} / \mathrm{l} 14 \% \mathrm{GHHb}$ and preincubated with $\mathrm{GHHb}$ plus $10 \mu \mathrm{mol} / 1$ glibenclamide respectively). In control experiments, preincubation with the three concentrations of gliclazide $(0.1,1$ and $10 \mu \mathrm{mol} / \mathrm{l})$ or glibenclamide $(10 \mu \mathrm{mol} / \mathrm{l})$ did not modify the vasodilator responses to $\mathrm{BK}$.

\section{Discussion}

In this study we show that human oxyhaemoglobin, when it is highly glycated (10 or $14 \% \mathrm{GHHb})$, and at concentrations found in human serum $[6,7]$, inhibits the vasodilatation induced by BK in human microvessels. Previous data from our laboratory indicate that nanomolar concentrations of GHHb produce an impairment of endothelium-dependent relaxations in aortic segments from normoglycaemic non-diabetic rats, which is mediated by the release of superoxide anions, as the endothelial dysfunction can be prevented with SOD $[4,5]$. A similar impairment by GHHb can be observed on the vasodilatation produced by exogenous NO, which is also reversed with SOD [5]. Therefore, we hypothesised that glycation of haemoglobin produces an increased release of reactive oxygen species, mainly superoxide anions, that inactivate the NO released by the endothelium [5]. It is reasonable to propose the same mechanism in the human vasculature. It is generally accepted that the vasodilatation induced by $\mathrm{BK}$ is principally mediated by $\mathrm{NO}$ in human small resistance vessels $[14,15]$. In our experimental conditions, more than $70 \%$ of the vasodilator response evoked by $\mathrm{BK}$ in human mesenteric microvessels was eliminated when the synthesis of NO was impaired with L-NAME. Furthermore, the vessels were precontracted by depolarisation with $\mathrm{KCl}$ to minimise the participation of hyperpolarizing substances released by the endothelium $[14,15]$. The 
Table 2. Influence of several concentrations of gliclazide on the inhibition induced by $10 \mathrm{nmol} / \mathrm{l} 14 \%$ glycated human oxyhaemoglobin on the $\mathrm{pD}_{2}$ values for bradykinin in human mesenteric microvessels

\begin{tabular}{ll}
\hline \multirow{2}{*}{ Control } & $\mathrm{pD}_{2}$ \\
& $7.81 \pm 0.095$ \\
$10 \mathrm{nmol} / 114 \% \mathrm{GHHb}$ & $(N=8 ; n=32)$ \\
& $7.31 \pm 0.067^{\mathrm{a}}$ \\
$10 \mathrm{nmol} / 114 \% \mathrm{GHHb}+0.1 \mu \mathrm{mol} / \mathrm{l}$ gliclazide & $7.33 \pm 0.114^{\mathrm{a}}$ \\
& $(N=3 ; n=5)$ \\
$10 \mathrm{nmol} / 114 \% \mathrm{GHHb}+1 \mu \mathrm{mol} / 1$ gliclazide & $7.56 \pm 0.104^{\mathrm{a}, \mathrm{b}}$ \\
& $(N=5 ; n=13)$ \\
$10 \mathrm{nmol} / 114 \% \mathrm{GHHb}+10 \mu \mathrm{mol} / 1$ gliclazide & $7.72 \pm 0.170$ \\
& $(N=4 ; n=9)$ \\
\hline
\end{tabular}

Data are means \pm SEM. ${ }^{\mathrm{a}} p<0.05$ vs control. ${ }^{\mathrm{b}} p<0.05$ vessels preincubated with GHHb. The number of patients $(N)$ and used segments $(n)$ are in parenthesis

remaining component of the vasodilatation seemed to be related to a cyclooxygenase-derived compound, as coincubation with indomethacin in addition to LNAME is necessary to totally eliminated the responses induced in these vascular segments by BK. Assuming that $\mathrm{GHHb}$ acts on the NO-mediated component of the BK-induced vasodilatation, GHHb only exerted its effect in control or indomethacin preincubated vessels but it lacked any additional impairment in vessels preincubated with L-NAME.

During the last years, it has become increasingly evident that the generation of reactive oxygen species plays a crucial part in developing diabetic vascular complications [16-18]. Indeed, there is an increase of oxidative stress even at early stages of diabetes in children and adolescents [19]. In addition, protein glycation is one of the main sources of free radicals in diabetes [18]. In our study, the consistent mechanism by which $\mathrm{GHHb}$ interferes with the endothelium-dependent relaxation in human vessels likely involves superoxide anions. Supporting this assumption, SOD but not catalase or dimethylthiourea abolished this effect of GHHb. These data agree with our previous results in rat vessels. The effect of GHHb on NO-mediated responses was mainly due to release of superoxide anions, as preincubation with SOD eliminated the impairment of endothelium-dependent NO-mediated relaxations, whereas catalase or deferoxamine were ineffective, indicating a weak role for hydroxyl radicals or hydrogen peroxide [5]. Although in this study we have not directly excluded other possibilities mediating the effect of GHHb, its reversion by SOD and by another unspecific antioxidant like ascorbic acid, as well as the absence of any effect on the vasodilatation not mediated by the interference with NO, strongly support the hypothesis that the most suitable mechanism is the generation of superoxide anions which in turn inactivate the NO released
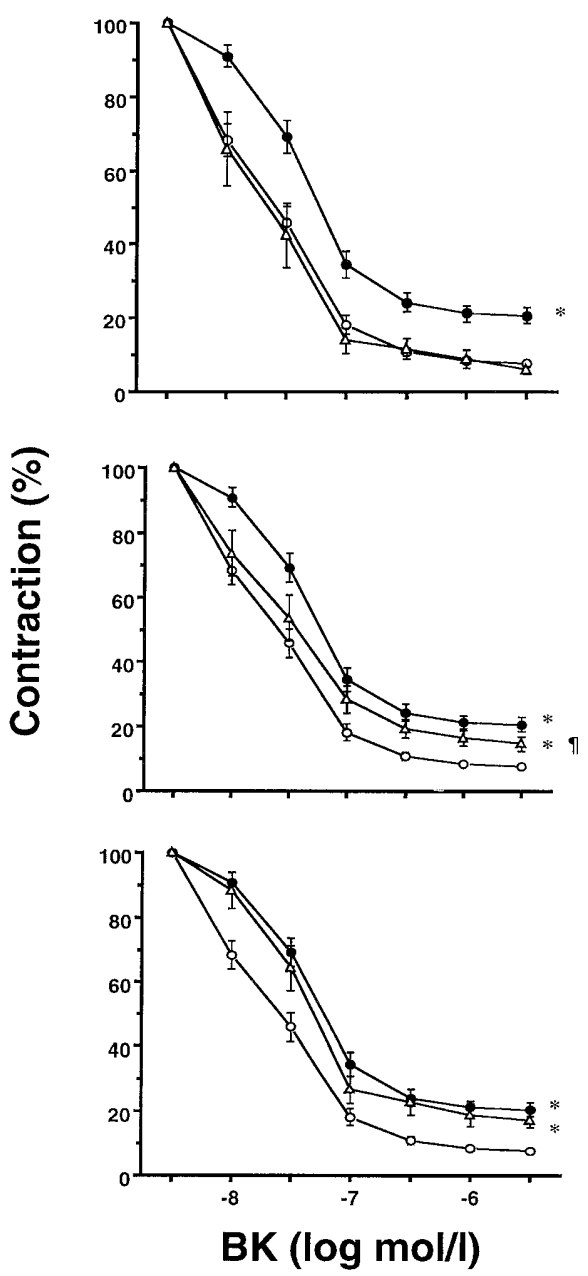

Fig. 6. Interference by preincubation with three different concentrations (Top: $10 \mu \mathrm{mol} / 1, n=9$; Middle: $1 \mu \mathrm{mol} / \mathrm{l}, n=13$; Bottom: $0.1 \mu \mathrm{mol} / \mathrm{l}, n=5)$ of gliclazide $(\Delta)$ on the impairment induced by $10 \mathrm{nmol} / \mathrm{l} 14 \% \mathrm{GHHb}(\boldsymbol{O}, n=19)$ of the control $(\bigcirc, n=32)$ responses to bradykinin $(\mathrm{BK})$ in human mesenteric microvessels. Data are expressed as means \pm SEM of the percentage of the residual contraction from the responses elicited by $35-50 \mathrm{mmol} / \mathrm{l} \mathrm{KCl}$ which ranged between 5 to $8 \mathrm{mN} /$ $\mathrm{mm}$, without differences among treatments. Vascular segments used for each curve $(n)$ were obtained from at least three different patients. $* p<0.05$ vs respective control curve. $\uparrow p<0.05$ vs curve with $\mathrm{GHHb}$

by the endothelium. Also in agreement with our hypothesis, another study showed [20] that superoxide anions are generated in glycated proteins almost 50fold more than in non-glycated proteins.

Further experiments were designed to evaluate the effects of two oral hypoglycaemic drugs, gliclazide and glibenclamide. They both have rather similar metabolic actions but gliclazide, in addition, has an antioxidant effect $[11,12]$. In agreement with the results with SOD and ascorbic acid, concentrations of gliclazide in the micromolar range were able to prevent the GHHb-induced impairment of endothelium-dependent relaxations, whereas similar concentrations of glibenclamide were not effective. Note 
that such concentrations of gliclazide are therapeutic in plasma [10]. This action of the drug helps to explain the recently described improvements achieved in endothelial dysfunction observed in alloxan-induced diabetic rabbits [21].

The role of impaired endothelial function in the pathological vasoactive responses observed in animals or humans with diabetes have been analysed by several studies, using both in vitro and in vivo preparations [22-26]. Our experimental approach allowed us to test a single effect on vascular segments from subjects without diabetes or any other vascular disease thus excluding other possible alterations that could be present in vessels from patients with diabetes. Concerning the possible pathophysiological relevance for the vasoactive effects of $\mathrm{GHHb}$ as a source of superoxide anions, note that a high percentage of $\mathrm{HbA}_{1 \mathrm{c}}$, is frequent in patients with poor glycaemic control [27]. Furthermore, the development of microvascular disease is associated with high percentages of glycated haemoglobin. An $\mathrm{HbA}_{1 \mathrm{c}}$ of around $8 \%$ has been shown to increase the risk of microvascular disease $[28,29]$, a percentage grossly similar to the $10 \%$ of $\mathrm{HbA}_{1}$, that is the lower percentage needed to impair bradykinin-induced vasodilatation in our study.

It seems possible, however, that the production of reactive oxygen species from the protein glycation process is not limited to haemoglobin but could also affect other circulating or structural proteins. Nevertheless, haemoglobin possesses some properties that make it a good candidate for being a cause of diabetic endothelial dysfunction by this mechanism. It is sensitive to changes in glycaemic concentrations [27], it circulates freely in plasma in nanomolar concentrations [7] and it can penetrate into the vascular wall in non-pathological circumstances $[30,31]$. Very recently it has been shown that endothelial cells are able to incorporate cell-free haemoglobin, creating a new way for circulating haemoglobin to be in close contact with NO [32]. Finally, we have recently described both in vitro and in vivo a high correlation between $\mathrm{HbA}_{1 \mathrm{c}}$ values and endothelial dysfunction in rats with streptozotocin-induced diabetes $[8,9]$. This finding supports the possibility that glycohaemoglobin plays a part in the endothelial dysfunction associated with diabetes.

Acknowledgements. Supported by grants from CICYT (SAF 96-0142 and 98-0010), CAM (08.4/0027/1998), European Union (2FD97-0445-C02 and the Servier International Institute of Research (IRIS PHA-1702-027-ESP). Dr. C. Peiró is a recipient of a postdoctoral fellowship from the CAM.

\section{References}

1. Fortes ZB, Leme JG, Scivoletto R (1983) Vascular reactivity in diabetes mellitus: role of the endothelial cells. Br J Pharmacol 79: 771-781

2. Calvier A, Collier J, Vallance P (1992) Inhibition and stimulation of nitric oxide synthesis in the human forearm arterial bed of patients with insulin-dependent diabetes. J Clin Invest 90: 2548-2554

3. Bucala R, Tracey KJ, Cerami A (1991) Advanced glycosylation products quench nitric oxide and mediate defective endothelium-dependent vasodilation in experimental diabetes. J Clin Invest 87: 432-438

4. Rodríguez-Mañas L, Arribas S, Girón C, Villamor J, Sánchez-Ferrer CF, Marín J (1993) Interference of glycosylated human hemoglobin with endothelium-dependent responses. Circulation 88: 2111-2116

5. Angulo J, Sánchez-Ferrer CF, Peiró C, Marín J, RodríguezMañas L (1996) Impairment of endothelium-dependent relaxation by increasing percentages of glycosylated human hemoglobin. Possible mechanisms involved. Hypertension 28: 583-592

6. Dacie J, Lewis SM (1984) Practical hematology, 6th edn. Churchill Livingstone, Edinburgh

7. Tietz NW (1990) Clinical guide to laboratory tests, 2nd edn. Saunders, Philadelphia

8. Angulo J, Rodríguez-Mañas L, Peiró C, Neira M, Marín J, Sánchez-Ferrer C (1998) Impairment of nitric oxide-mediated relaxations in anaesthetized autoperfused streptozotocin-induced diabetic rats. Naunyn Schmiedebergs Arch Pharmacol 356: 529-537

9. Rodríguez-Mañas L, Angulo J, Peiró C et al. (1998) Endothelial dysfunction and metabolic control in streptozotocin-induced diabetic rats. Br J Pharmacol 123: 1495-1502

10. Palmer KJ, Brogden RN (1993) Gliclazide. An update of its pharmacological properties and therapeutic efficacy in non-insulin dependent diabetes mellitus. Drugs 46: 92-125

11. Scott NA, Jennings PE, Brown J, Belch JJF (1991) Gliclazide: a free radical scavenger. Eur J Pharmacol 208: 175-177

12. Jennings PE, Scott NA, Santabadi AR, Belch JJF (1992) Effects of gliclazide on platelet reactivity and free radicals in type II diabetic patients: clinical assessments. Metabolism 41: 36-39

13. Mulvany MJ, Halpern W (1977) Contractile properties of small arterial resistance arteries in spontaneously hypertensive and normotensive rats. Circ Res 4: 19-26

14. Ohlmann P, Martínez MC, Schneider F, Stoclet JC, Andriantsitohaina R (1997) Characterization of endothelium-derived relaxing factors released by bradykinin in human resistance arteries. Br J Pharmacol 121: 657-664

15. Kemp BK, Cocks TM (1997) Evidence that mechanisms dependent and independent of nitric oxide mediate endothelium-dependent relaxation to bradykinin in human small resistance-like coronary arteries. $\mathrm{Br} \mathrm{J}$ Pharmacol 120: 757-762

16. Ceriello A, Quatraro A, Giugliano D (1993) Diabetes mellitus and hypertension: the possible role of hyperglycaemia through oxidative stress. Diabetologia 36: 265-266

17. Giugliano D, Ceriello A, Paolisso G (1996) Oxidative stress and diabetic vascular complications. Diabetes Care 19: $257-267$

18. Tesfamariam B (1994) Free radicals in diabetic endothelial cell dysfunction. Free Radic Biol Med 16: 383-391

19. Domínguez C, Ruiz E, Gussinye M, Carrascosa A (1998) Oxidative stress at onset and in early stages of type I diabetes in children and adolescents. Diabetes Care 21: 1736-1742 
20. Mullarkey CJ, Edelstein D, Brownlee M (1990) Free radical generation by early glycation products: a mechanism for accelerated atherogenesis in diabetes. Biochem Biophys Res Commun 173: 932-939

21. Pagano PJ, Griswold MC, Ravel D, Cohen RA (1998) Vascular action of the hypoglycaemic agent gliclazide in diabetic rabbits. Diabetologia 41: 9-15

22. Calvier A, Collier J, Vallance P (1992) Inhibition and stimulation of nitric oxide synthesis in the human forearm arterial bed of patients with insulin-dependent diabetes. J Clin Invest 90: 2548-2554

23. Cohen RA (1993) Dysfunction of vascular endothelium in diabetes mellitus. Circulation 87:[Suppl V]:V67-V76

24. Pieper GM (1998) Review of alterations in endothelial nitric oxide production in diabetes. Protective role of arginine on endothelial dysfunction. Hypertension 31: 1047-1060

25. Kamata K, Miyata N, Kasuya Y (1989) Involvement of endothelial cells in relaxation and contraction responses of the aorta to isoproterenol in naive and streptozotocininduced diabetic rats. J Pharmacol Exp Ther 249: 890-894

26. Durante W, Sen AK, Sunahara FA (1988) Impairment of endothelium-dependent relaxation in aortae from spontaneously diabetic rats. Br J Pharmacol 94: 463-468
27. Jovanovic L, Peterson CM (1981) The clinical utility of glycosylated hemoglobin. Am J Med 70: 331-337

28. The Diabetes Control and Complications Trials Research Group (1993) The effect of intensive treatment of diabetes on the development and progression of long-term complications in insulin-dependent diabetes mellitus. N Engl J Med 329: 977-986

29. UK Prospective Diabetes Study (UKPDS) Group (1998) Intensive blood-glucose control with sulphonylureas or insulin compared with conventional treatment and risk of complications in patients with type 2 diabetes (UKPDS 33). Lancet 352: 837-853

30. Hongo K, Ogawa H, Kassel NF et al. (1988) Comparison of intraluminal and extraluminal-inhibitory effects of hemoglobin on endothelium-dependent relaxation of rabbit basilar artery. Stroke 19: 1550-1555

31. Stary HC, Blankenhorn DH, Chandler AB et al. (1992) A definition of the intima of human arteries and of its atherosclerosis-prone regions. A report from the Committee on Vascular Lesions of the Council on Atherosclerosis, American Heart Association. Circulation 85: 391-405

32. Faivre-Fiorina B, Caron A, Fassot C et al. (1999) Presence of hemoglobin inside aortic cells after cell-free hemoglobin administration in guinea-pigs. Am J Physiol 276: H766$\mathrm{H} 770$ 